\title{
Diagnosis of non-cardiac fetal malformations during mid-trimester anomaly scan: Does three-dimensional ultrasonography have any added value?
} Original

Article

\author{
Somayya M. Sadek
}

Department of Obstetrics \& Gynecology, Faculty of Medicine, Zagazig University, Egypt

\begin{abstract}
Objective: To determine if there is any added value of 3D US examination in diagnosis of fetal malformations during mid-trimester anomaly scan.

Design: A prospective observational study.

Setting: Obstetrics and Gynecology Ultrasound Unit, Zagazig University Hospitals.

Patients and Methods: Pregnant women referred for mid-trimester anomaly scan were prospectively evaluated by $2 \mathrm{D}$ US. Fetuses suspected to have malformation by 2D US or with increased risk of a recurrence or strong family history of a congenital abnormality were evaluated by 3D US. Women confirmed to have fetal malformations postnatally were included.

Results:Seven hundred and seventy-six malformations were confirmed postnatally. 2D US established the diagnosis of $752(96.9 \%)$ malformations and 3D US diagnosed 770 (99.2\%) malformations and the difference was highly significant [McNemar chi-squared statistic $=16, p=<0.0001]$. Seven hundred and fifty-two malformations were diagnosed by both 2D and 3D US. Eighteen malformations were detected exclusively by 3D US. 3D US was superior to 2D in evaluating cranial, facial and limb malformations. A cleft soft palate, hand abnormalities $(n=3)$ and feet abnormalities $(n=2)$ were missed by both 2D and 3D US.

Conclusion: Three dimensional US added value in diagnosis of some types of fetal malformations. Rather than representing an alternative, 3D US is complementary to the conventional 2D US in the field of prenatal diagnosis.
\end{abstract}

Key Words: Fetal, malformations, three-dimensional, two-dimensional, Ultrasound

Received: $16^{\text {th }}$ July 2019, Accepted: $28^{\text {th }}$ July 2019

Corresponding Author: Somayya M. Sadek, Department of Obstetrics \& Gynecology, Faculty of Medicine, Zagazig University, Egypt, Tel.: 00201128220420,E-mail: somayya74@gmail.com

ISSN: 2090-7625, November 2019, Vol.9, No. 4

\section{INTRODUCTION}

Three-dimensional (3D) ultrasound imaging permits examiners to replace the imaginary reconstruction of twodimensional (2D) images to actual 3D visualization of anatomical structures ${ }^{[1]}$. The ability to display a volume in planes in which direct image acquisition is impossible represents the most important advance that $3 \mathrm{D}$ US has to offer $^{[2]}$. 3D US is also beneficial in affording the ability of post-examination interactive review and the availability of a variety of rendering methods that allow visualization of different characteristics of the same structure. Moreover, volume measurements are more accurate including volume measurements of irregular objects, and imaging of the fetal skeleton and spatial presentation of blood vessels arborization are much improved. Furthermore, encouraging the bond between the mother and her fetus, the possibility to standardize ultrasound examinations, the ability to transmit data over networks for consultation in tertiary care centers and the potential to use offline software programs as an interactive educational tool, adds to the value of $3 \mathrm{D} \mathrm{US}^{[3-8]}$.

To be incorporated to the daily clinical practice, wide acceptance will come if there is scientific evidence that $3 \mathrm{D}$ US adds information to what is currently provided by $2 \mathrm{D}$ US. Some of the studies found that $3 \mathrm{D}$ US was advantageous for the visualization of congenital malformations ${ }^{[9,10]}$; whereas others found that $3 \mathrm{D}$ US did not provide significant additional information over what was provided by $2 \mathrm{D} \mathrm{US}{ }^{[11]}$, thus further investigations are required to come to a consensus.

Mid-trimester anomaly scan using 2D US is now widely practiced and most of fetal malformations are diagnosed during its period. Moreover, the fetus during scanning is surrounded by a sufficient amount of amniotic fluid and is 
freely moving, thus 3D US volumes can be acquired with clear view of all items in need for review within the fetus. Therefore, this study was conducted to determine if there is any added value of 3D US examination in diagnosis of fetal malformations during mid-trimester anomaly scan.

\section{PATIENTS AND METHODS}

\section{Study population:}

From January 2012 to December 2016, after approval by the institutional review board of Zagazig University (ZU-IRB\#4764-14-10-2011), pregnant women referred for mid-trimester anomaly scan were prospectively evaluated by both 2D and 3D US after an informed oral consent. All patients were provided with all of the necessary information about the study before documentation of their consent. Fetal heart defects were out of scope of the study since they could not be assessed by the 3D US, as spatiotemporal image correlation (STIC) technology was unavailable.

In order to compare between the two modalities for the detection of fetal malformations, only the patients who were confirmed to have fetal abnormalities by postnatal follow up were included in the study. Confirmation of fetal malformations was performed by post-natal physical and/ or radiological examinations as needed.

\section{$2 D$ and $3 D$ sonography:}

Both 2D US and 3D US were done using a Voluson E6 machine (GE Medical Systems, Zipf, Austria). A transabdominal convex array volume RAB6-D transducer was employed for $2 \mathrm{D}$ examination and volume dataset acquisition

At first, standard fetal scanning was conducted using 2D US following the International Society of Ultrasound in Obstetrics and Gynecology (ISUOG) practice guidelines for performance of the routine midtrimester fetal ultrasound scan ${ }^{[12]}$. An initial 2D sonographic diagnosis of fetal malformations was established and recorded.

Representative 3D volume data sets of the fetal anatomy including the head, face, chest, abdomen, limbs and spine were acquired for fetuses suspected to have malformation by conventional 2D US or in cases with higher risk of a recurrence or strong family history of a congenital abnormality. During 3D volume acquisition, special attention was paid to the biophysical prerequisites to ensure an optimal image quality, absence of fetal movements, favorable position of the region of interest in relation to the probe and sufficient amount of amniotic fluid around this region. Approximately 2 to 5 volume data sets were obtained per anomaly. This, as thorough as possible, examination aimed to document fetal anatomical structures and congenital malformations. Volume data were stored on the hard drive of the US machine.

\section{Review of images:}

Later, volume data sets were processed and examined for each patient in order to establish a diagnosis by 3D US. The 3D US volume data were displayed in three modes: the multiplanar mode, rendering modes and tomographic ultrasound imaging (TUI). The multiplanar images were rotated around the three axes (X, Y, or Z) into a standard anatomic orientation to display simultaneously the sagittal, transverse and coronal planes through the fetus at the region of interest; these could then be studied by navigation through each plane independently. Rendered images were obtained by selection of the region of interest using a rectangular box in each of the three planes. Volume manipulation was performed to achieve high quality images including the electronic scalpel and threshold as well as brightness and contrast adjustments. Four types of rendering modes were used; surface rendering/HDlive, maximum mode, minimum mode and glass body mode combined with color or power Doppler. The surface rendering/Hdlive images showed a smoothly contoured lifelike view, which was used to evaluate the facial features and extremities. The surface mode was also used to demonstrate internal structures when parts of the fetal anatomy were removed by the electronic scalpel to render the surface of the selected section. The skeleton visualization with higher contrast (especially the spines, ribs and scapulae) was enabled by highlighting the inner bone structures on maximum mode images. The combined glass body/color or Doppler mode was used to demonstrate the fetal vascular system. Utilizing TUI, multiple slices of the acquired volume of the studied region were generated, enabling accurate mapping of the malformation aided by modifying the distance between and number of slices. Figures 1-8 show some malformations visualized and studied by different modes of $3 \mathrm{D}$ US. The time needed for manipulating each patient's volumes into readable slices and surface rendered displays, lied between 10 and 30 minutes.

The final 3D US images were interpreted and recorded. Then, they were compared to 2D US stored data. A subjective evaluation of whether the 3D US images were advantageous when compared with the 2D US findings was provided. The 3D technique was defined as advantageous when it provided additional information regarding localization, size and depth of a malformation, changes the diagnosis, or when a malformation undetected with 2D US was found. 


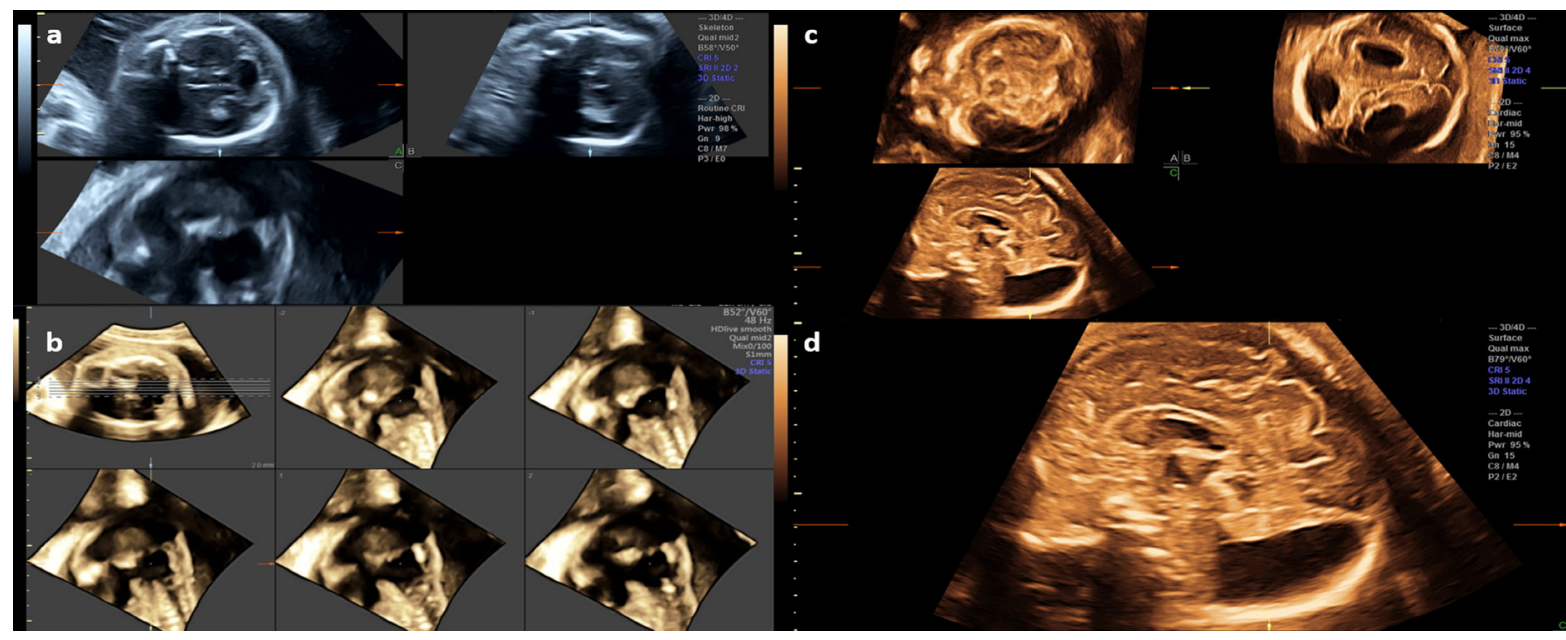

Fig 1: Dandy-Walker malformation, multiplanar view (a) and Tomographic Ultrasound imaging (TUI) (b) showing agenesis of the vermis, multiplanar view (c) and reconstructed mid-sagittal view of the brain (d) showing upwards rotation of the hypoplastic vermis

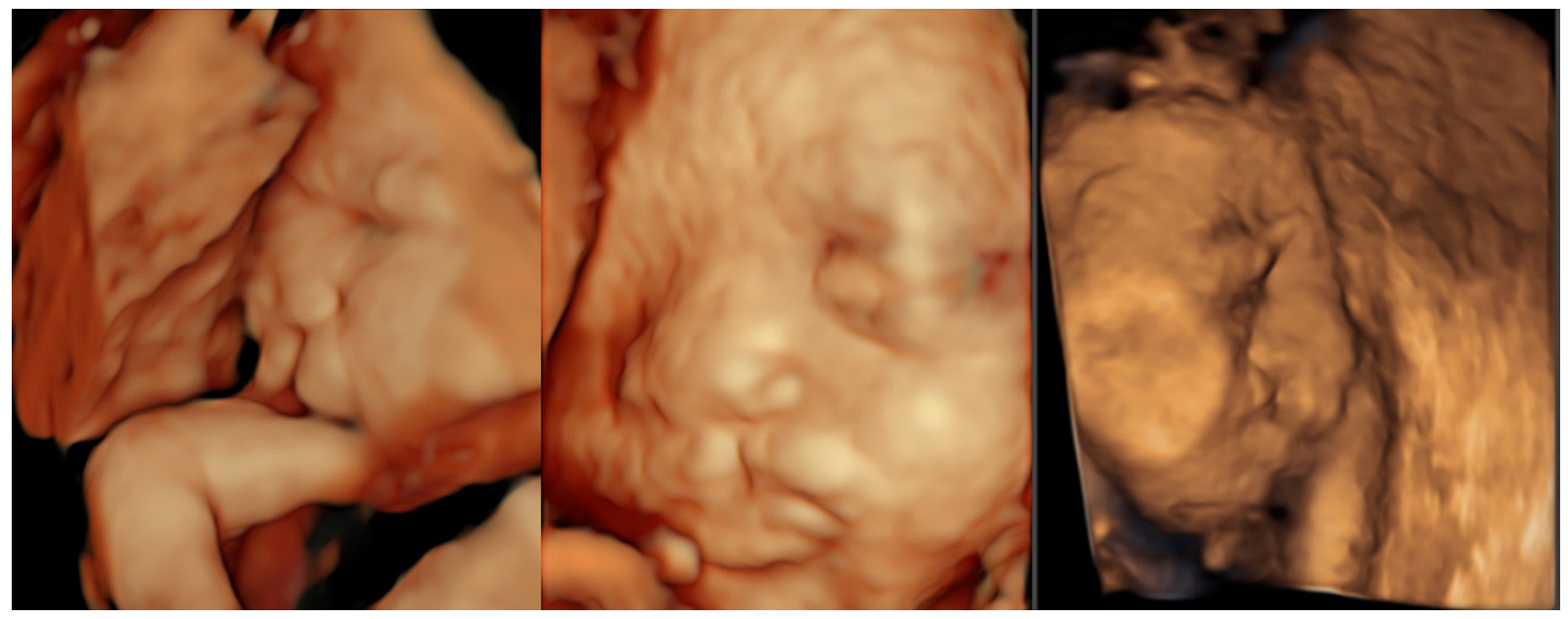

Fig 2: Cleft lip (surface rendered)

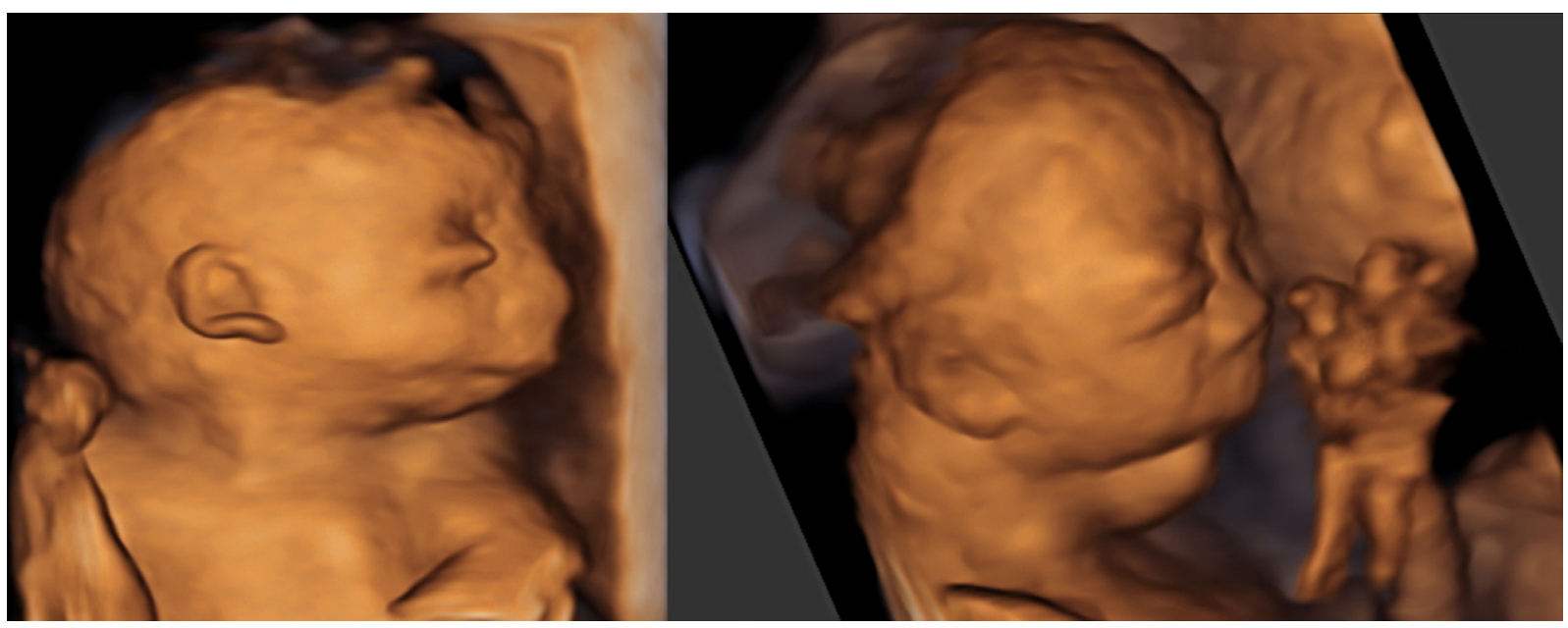

Fig 3: Micrognathia (surface rendered) 


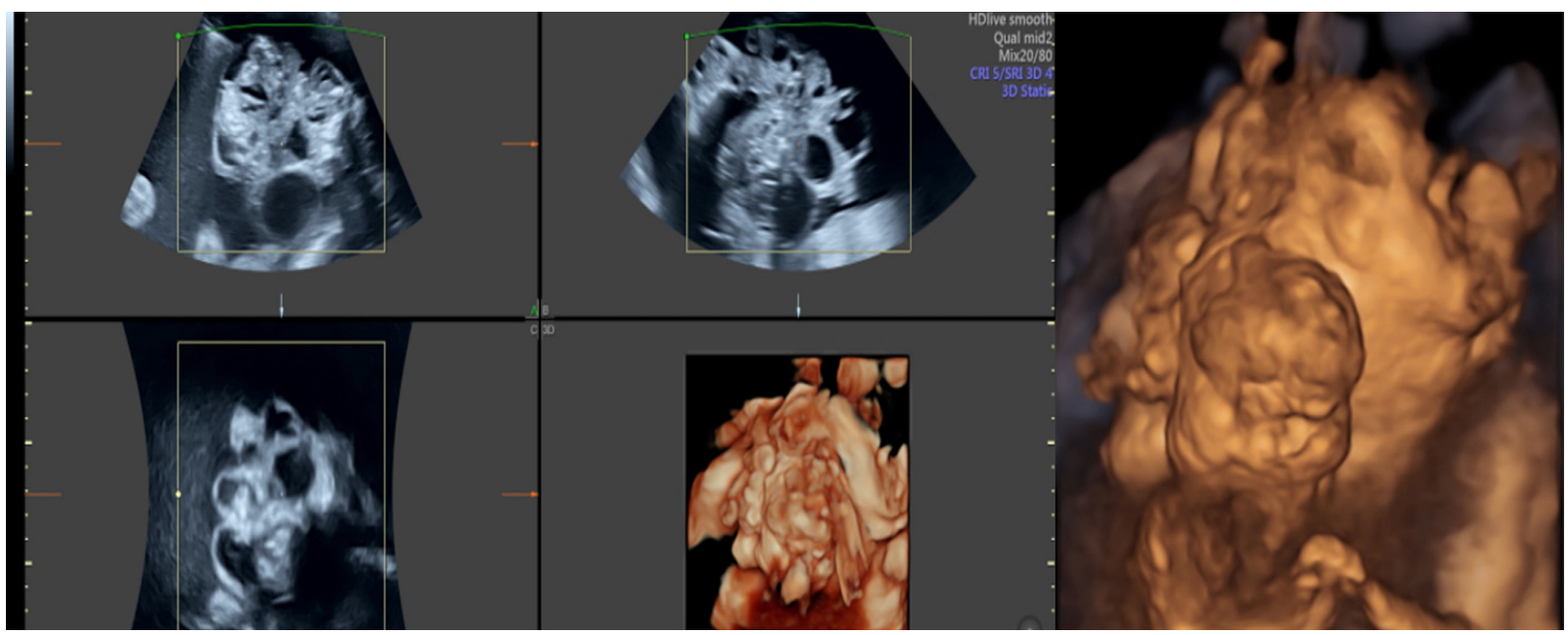

Fig 4: Oro-pharyngeal teratoma (surface rendered)

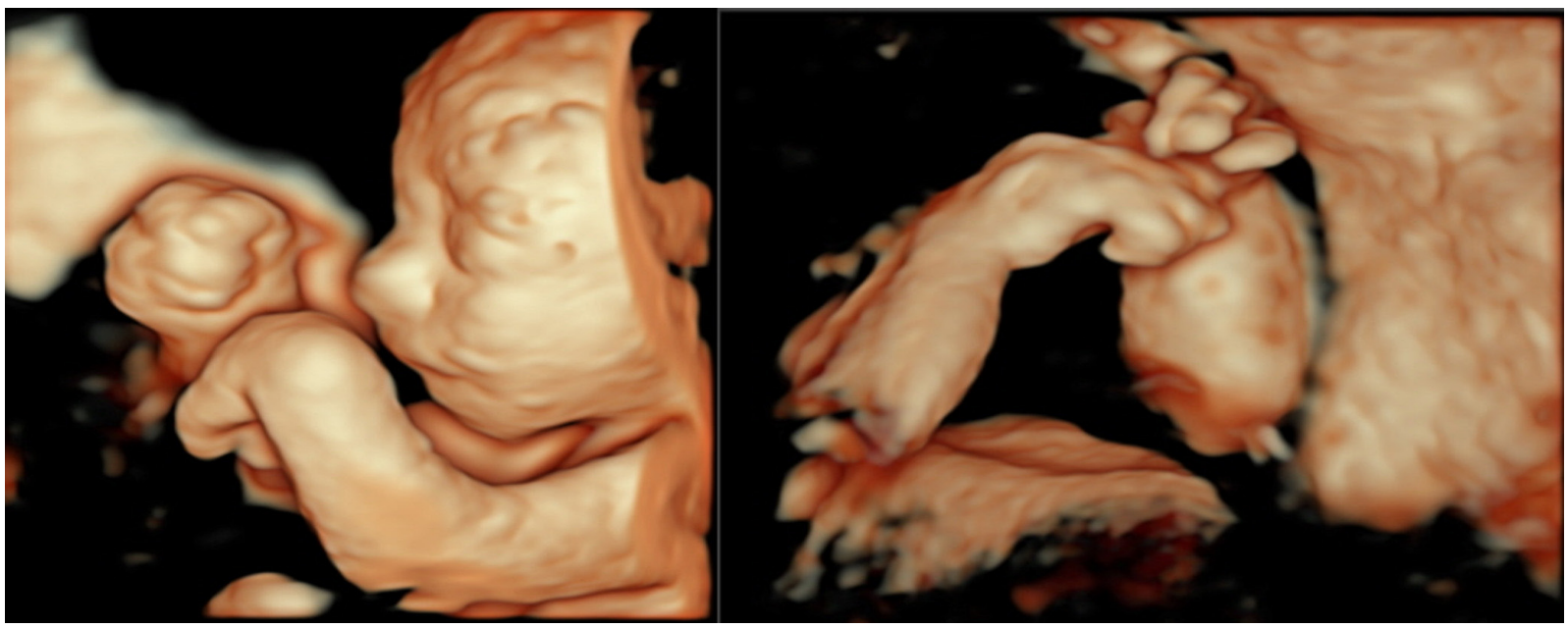

Fig 5: Hands abnormalities (surface rendered)

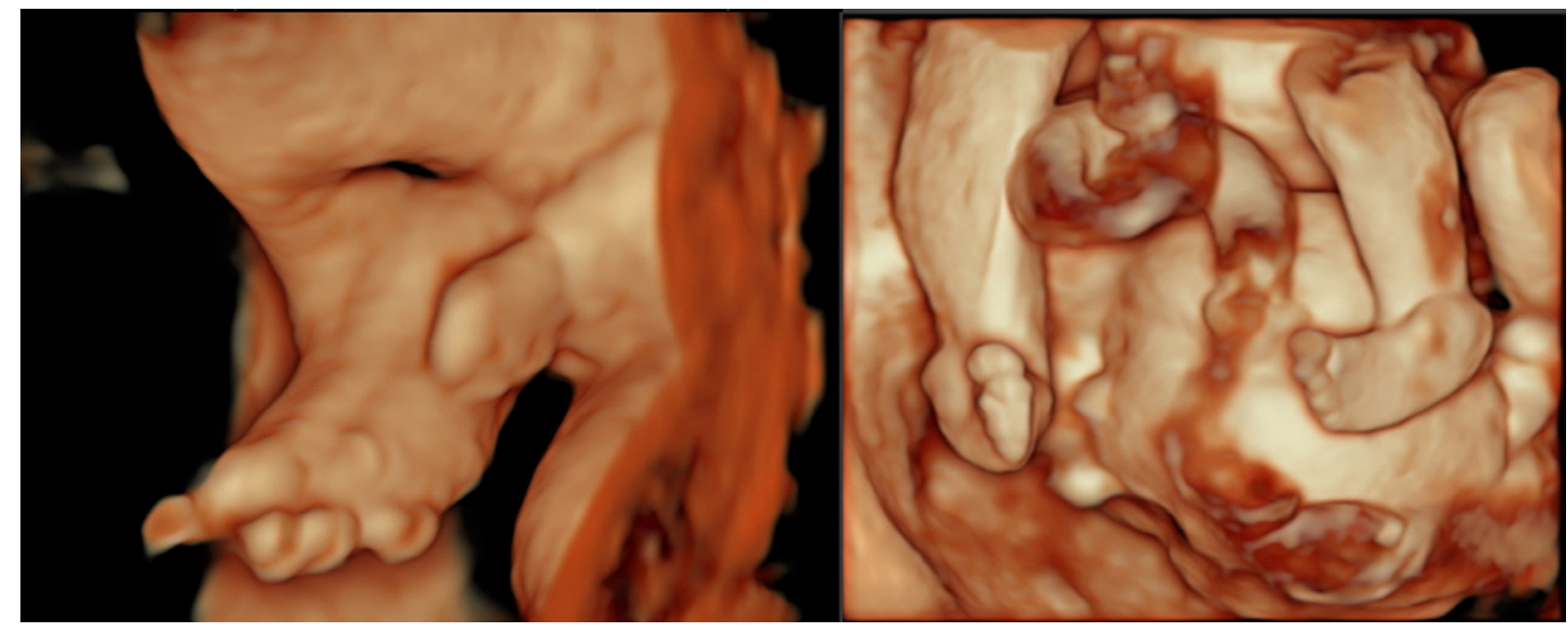

Fig 6: Feet abnormalities (surface rendered) 


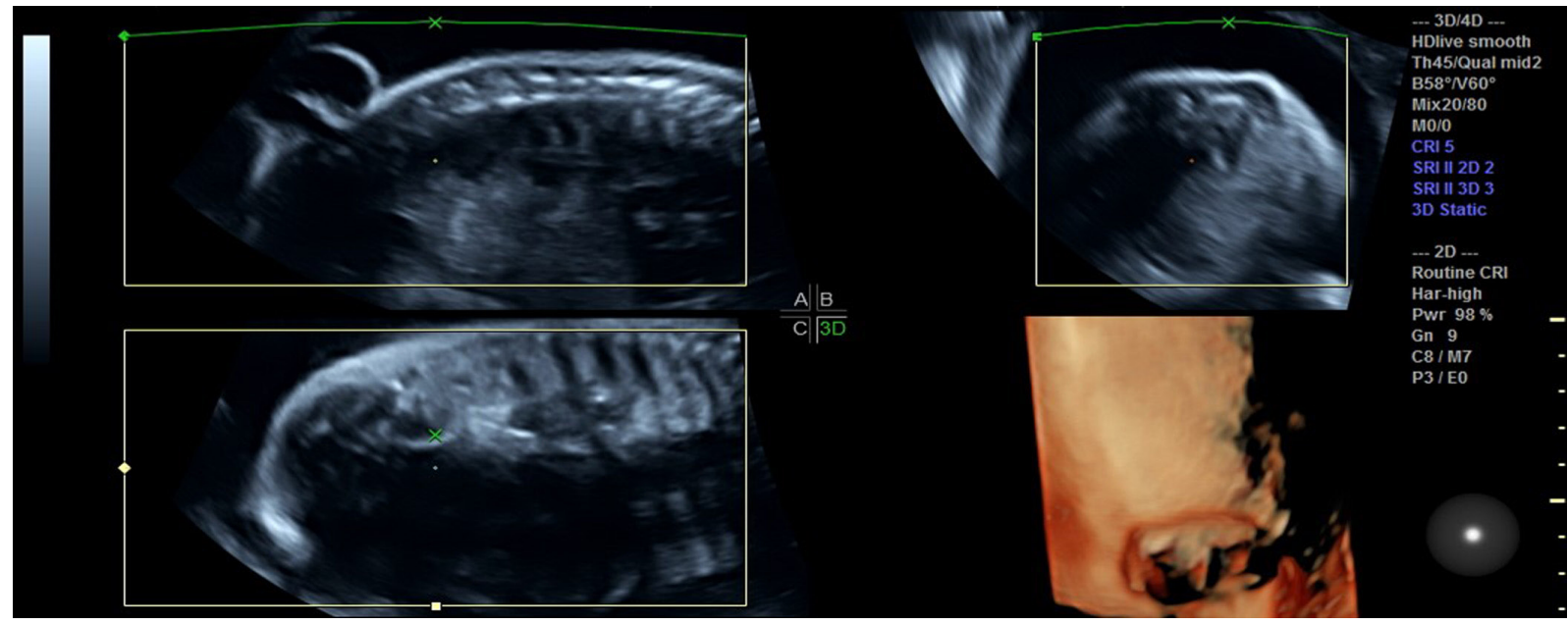

Fig 7: Spina bifida (surface rendered)

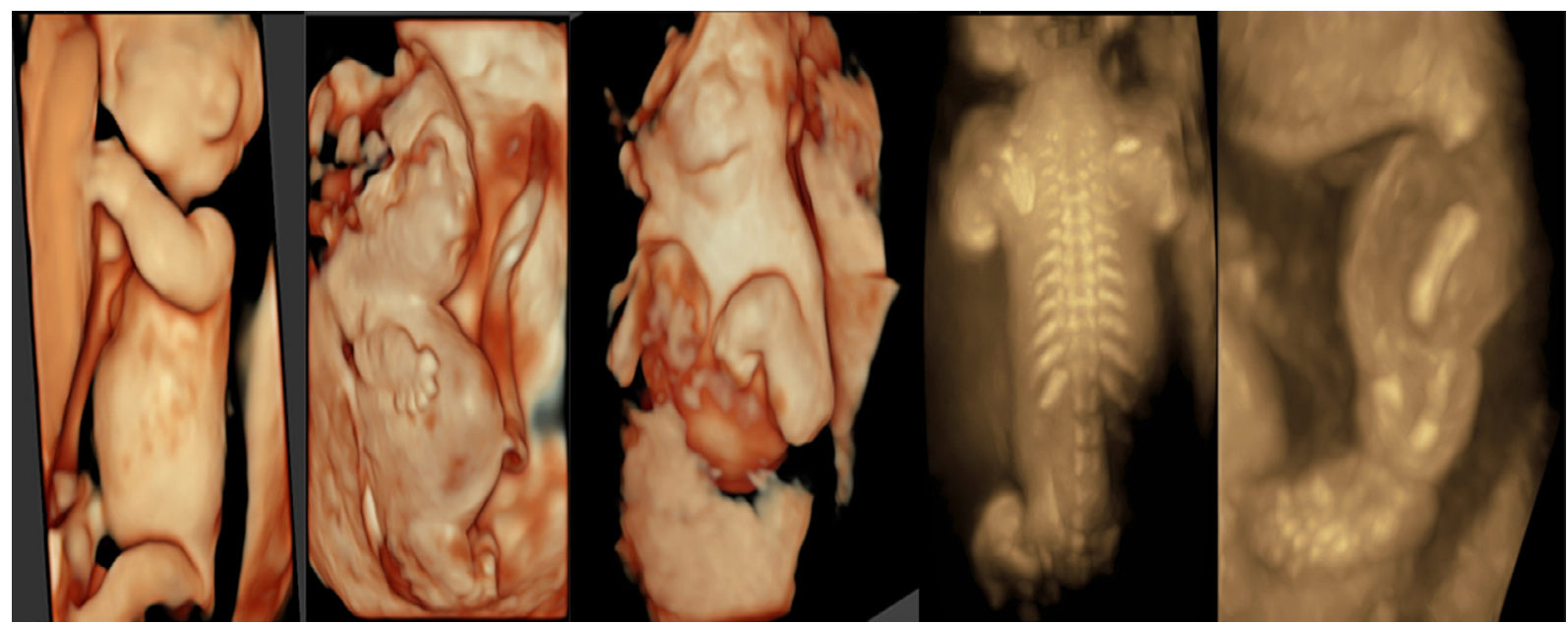

Fig 8: Skeletal abnormalities (surface rendered and maximum mode)

\section{Statistical analysis:}

The differences between 2D US and 3D US in identifying fetal malformations were analyzed by McNemar test. Statistical significance was archived at a $p$ value of less than 0.05 . The statistical analysis was performed using SPSS $\odot$ version 21 [IBM $\odot$ Corp., Armonk, NY].

\section{RESULTS}

During the period of the study, mid-trimester anomaly scan was performed for 5641 women with malformations confirmed postnatally in 534 women. Five hundred and sixty five fetuses (503 singleton and 31 pairs of twins) with a total of 776 confirmed malformations were included in the study. The mean age of the 534 women was 29.8 years (range, 21-40years) and the mean gestational age of the fetuses at sonographic examination was 22 weeks (range, 202 .(25-D US established the diagnosis of $752(96.9 \%)$ malformations, whereas, 3D US diagnosed 770 (99.2\%) malformations and the difference was highly significant [McNemar chi-squared statistic $=16, p=<0.0001] \quad$ (Tables 1 and 2). The combined use of 2D US and 3D US perfectly diagnosed $99.2 \%$ of the malformations. Seven hundred and fifty two malformations $(96.9 \%)$ were diagnosed by both $2 \mathrm{D}$ and $3 \mathrm{D}$ US. In 18 malformations $(2.3 \%)$, the defects were detected exclusively by 3D US; agenesis of corpus callosum $(n=2)$, iniencephaly $(n=1)$, Dandy Walker malformation $(\mathrm{n}=3)$, exophthalmos $(\mathrm{n}=1)$, cleft palate $(n=1)$, micrognathia $(n=4)$, low set ear $(n=3)$.

The combined use of 2D US and 3D US perfectly diagnosed $99.2 \%$ of the malformations. Seven hundred and fifty two malformations $(96.9 \%)$ were diagnosed by both $2 \mathrm{D}$ and $3 \mathrm{D}$ US. In 18 malformations $(2.3 \%)$, the defects were detected exclusively by 3D US; agenesis of corpus callosum $(n=2)$, iniencephaly $(n=1)$, Dandy Walker malformation $(n=3)$, exophthalmos $(n=1)$, cleft palate $(n=1)$, micrognathia $(n=4)$, low set ear $(n=3)$ and hand abnormalities $(n=3)$. A Cleft soft palate, hand abnormalities $(n=3)$ and feet abnormalities $(n=2)$ were missed by both 2D and 3D US. 3D US was particularly superior to $2 \mathrm{D}$ in evaluating cranial (6 out of 163 cases, $3.7 \%$,) facial (9 out of 47, 19.1\%) and limb (3 out of 78, 3.8\%) malformations (Table 3). No additional information was obtained by $3 \mathrm{D}$ US regarding neck, thoracic and abdominal malformations. 
Table 1: Visualization of fetal malformation by 2D and 3D US and their postnatal findings

\begin{tabular}{lccc}
\hline Malformation & Detected with 2D US (n) & Detected with 3D US (n) & Postnatally confirmed (n) \\
\hline Head & 195 & 210 & 211 \\
Neck and thorax & 94 & 94 & 266 \\
Abdomen & 266 & 111 & 266 \\
Musculo-skeletal & 108 & 89 & \\
Fetal hydrops & 89 & $716(99.2 \%)$ \\
\hline
\end{tabular}

2D US, 2 dimensional ultrasound; 3D US, 3 dimensional ultrasound

Table 2: Comparison of 2D and 3D US findings in 776 malformations confirmed postnatally

\begin{tabular}{|c|c|c|c|}
\hline \multirow{2}{*}{ 3D US diagnosis } & \multicolumn{3}{|c|}{ 2D US diagnosis } \\
\hline & Diagnosed cases & Missed cases & Total \\
\hline Diagnosed cases & 752 & 18 & $770 *$ \\
\hline \multirow[t]{2}{*}{ Missed cases } & 0 & 6 & 6 \\
\hline & $752 *$ & 24 & 776 \\
\hline
\end{tabular}

$* P=<0.0001$ for comparison of malformations diagnosed by $3 \mathrm{D}$ versus $2 \mathrm{D}$ US

Table 3: Diagnostic information provided by 3D US as compared to 2D US in $770 *$ postnatally confirmed malformations

\begin{tabular}{|c|c|c|c|}
\hline Malformation & Similar & Advantageous & Postnatal \\
\hline 1. Head: (n) & 195 & 15 & 210 \\
\hline Cranium (n) & 157 & 6 & 163 \\
\hline Acrania & 11 & 0 & 11 \\
\hline Anencephaly & 32 & 0 & 32 \\
\hline Ventriculomegaly & 52 & 0 & 52 \\
\hline Microcephaly & 8 & 0 & 8 \\
\hline Schizenccephaly & 1 & 0 & 1 \\
\hline Agenesis of corpus callosum & 9 & 2 & 11 \\
\hline Iniencephaly & 1 & 1 & 2 \\
\hline
\end{tabular}




\begin{tabular}{|c|c|c|c|}
\hline Encephalocele & 8 & 0 & 8 \\
\hline Mega cysterna magna & 3 & 0 & 3 \\
\hline Dandy-Walker malformation & 12 & 3 & 15 \\
\hline Holoprosencephaly & 18 & 0 & 18 \\
\hline Strawberry head & 1 & 0 & 1 \\
\hline Brain mass & 1 & 0 & 1 \\
\hline Face (n) & 38 & 9 & 47 \\
\hline Exophthalmos & 1 & 1 & 2 \\
\hline Hypotelorism & 1 & 0 & 1 \\
\hline Hypertelorism & 5 & 0 & 5 \\
\hline Microphthalmia & 1 & 0 & 1 \\
\hline Anophthalmia & 1 & 0 & 1 \\
\hline Cleft lip and palate & 4 & 1 & 5 \\
\hline Micrognathia & 16 & 4 & 20 \\
\hline Absent nasal bone & 7 & 0 & 7 \\
\hline Low set ear & 0 & 3 & 3 \\
\hline Hemangioma & 1 & 0 & 1 \\
\hline Oro-pharyngeal teratoma & 1 & 0 & 1 \\
\hline 2. Neck and Thorax (n) & 94 & 0 & 94 \\
\hline Cystic hygroma & 65 & $\mathbf{0}$ & 65 \\
\hline Unilateral CCAM & 5 & 0 & 5 \\
\hline Diaphragmatic hernia & 8 & 0 & 8 \\
\hline Pleural effusion & 14 & 0 & 14 \\
\hline Pulmonary sequestration & 1 & 0 & 1 \\
\hline Ectopia cordis & 1 & 0 & 1 \\
\hline 3. Abdomen: (n) & 266 & 0 & 266 \\
\hline Abdominal wall (n) & 24 & $\mathbf{0}$ & 24 \\
\hline Gastroschisis & 2 & $\mathbf{0}$ & 2 \\
\hline Omphalocele & 18 & 0 & 18 \\
\hline
\end{tabular}


Body stalk anomaly

Cloacal exestrophy

Genito-urinary (n)

Pyelectasia

Hydroureter and/

or hydronephrosis

Megacystis

Renal agenesis

18

Renal hypoplasia

Pelvic kidney

2

Bilateral polycystic kidneys

16

Multicystic dysplastic kidney 22

Renal cyst

2

Ovarian cyst

Ambiguous genitalia

$\operatorname{GIT}(n)$

15

Oesophageal atresia

3

Duodenal atresia

2

Small intestinal obstruction

Anal atresia

2

Volvulus

Enteric duplication cyst

Ascites (n)

Meconium peritonitis (n)

4. Musculo-skeletal: (n)

Limbs (n)

108

Long bones shortening,

75

deformity or absence

Absent whole or

25

part of a limb
3

0

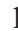

192

82

15

22

18

8

2

16

22

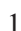

4

15

3

2

6

2

1

1

32

3

111

78

25 


\begin{tabular}{|c|c|c|c|}
\hline Hands abnormalities & 3 & 0 & 3 \\
\hline Feet abnormalities & 12 & 3 & 15 \\
\hline Spine (n) & 35 & 0 & 35 \\
\hline Spina bifida & 21 & 0 & 21 \\
\hline Kyphoscoliosis & 12 & $\mathbf{0}$ & 12 \\
\hline Sacro-coccygeal teratoma & 5 & 0 & 5 \\
\hline Sacral agenesis & 3 & 0 & 3 \\
\hline Thoracic hypoplasia (n) & 1 & 0 & 1 \\
\hline Short ribs (n) & 7 & 0 & 7 \\
\hline Hypomeniralization (n) & 3 & 0 & 3 \\
\hline FADS (n) & 1 & 0 & 1 \\
\hline 5. Fetal hydrops (n) & 1 & 0 & 1 \\
\hline \multirow{2}{*}{ Total (n) } & 89 & 0 & 89 \\
\hline & 752 & 18 & 770 \\
\hline
\end{tabular}

CCAM, congenital cystic adenomatoid malformation; FADS, fetal akinesia deformation sequence; $* 6$ cases missed by both 2D and 3D US

\section{DISCUSSION}

Since the first international conference for 3D/4D obstetric and gynecologic US held in Germany 1997, this method has gained a wide acceptance. ${ }^{[13]}$ A consensus conference was held by the American Institute of Ultrasound in Medicine in 2005, in which it was shown that 3D US has the ability to image an enormous number of obstetrical and gynecologic conditions. $^{[14]}$ However, questions were raised about the role of 3D US in prenatal diagnosis, improving diagnostic accuracy, more anomaly detection and the credibility of being routinely used in daily practice. ${ }^{[15]}$ Some authors are convinced that $3 \mathrm{D}$ imaging is able to convey additional image information ${ }^{[9,10,16]}$, other authors merely report comparable results ${ }^{[17-19]}$ and similar limitations as with conventional 2D US..$^{[1]}$

In the present work, concordance between ultrasonographic diagnosis and neonatal outcome was observed in $99.2 \%$ of the 3D US examinations alone and the combined use of 2D US and 3D US, and in $96.9 \%$ of the examinations performed by 2D US. The detection rates of 2D US and 3D US were statistically different for postnatally confirmed malformations. 2D
US was conformed to 3D US diagnosis in $96.9 \%$ of the cases. 3D US was more helpful in $2.3 \%$.

These results are comparable to those obtained by $\mathrm{Xu}$ et $a l .{ }^{[9]}$, who reported higher visualization rates for congenital malformations by $3 \mathrm{D}$ US $(92.7 \%$ versus $78 \%$; McNemar test, $p<0.05$ ). They also found that $3 \mathrm{D}$ US was superior to $2 \mathrm{D}$ US in $60 \%$ of the definitely diagnosed malformations. In the same vein, Dyson et al. ${ }^{[16]}$ reported on 63 patients with 103 malformations and found that 3D offered diagnostic advantages in about one half of the cases but only affected management in one patient. They found that 3D US was an adjunctive tool to 2DUS providing a more comprehensive image although only to be used as a targeted study to complement 2D US. However, $71 \%$ of the fetal malformations reported in their study were facial $(n=28)$, spinal $(n=10)$ and skeletal abnormalities $(n=36)$ which are reported to be more accurately diagnosed by 3D US.

In contrast, Goncalves et al. ${ }^{[17]}$ examined 99 fetuses (54 were normal and 45 had 82 malformations) and observed conformity between $2 \mathrm{D}$ and 3D/4D ultrasonography for $90.4 \%$ of the findings. The 
sensitivity $[92.2 \%$ vs $96.1 \%]$ and specificity $[76.4 \%$ vs $72.7 \%$ ] of $3 \mathrm{D} / 4 \mathrm{D}$ and $2 \mathrm{D} \mathrm{US}$, respectively, were insignificantly different (kappa=0.821; McNemarBowkeris test: $3.00, p=0.223$ ) in detection of congenital malformations confirmed postnatally. Scharf et al. ${ }^{[11]}$ found that 3D US did not provide significant additional information over what was provided by $2 \mathrm{D}$ US. They reported that the image resolution of the reconstructed planes is inferior to that of the acquisition planes making the quality of the $2 \mathrm{D}$ views that can be obtained traditionally higher than the views that are reconstructed from a $3 \mathrm{D}$ volume. They explained that it is merely the examiner brain that perceives the given anomaly in a faster and a more complete way if it is presented in the form of 3D images; it is not the quality of the physical visualization which is rated but the psychological effect which is generated in the examiner brain by the image presentation. Recently, the prospective blinded case-control study of Goncalves et al. ${ }^{[20]}$ included 148 fetuses to compare the accuracy of $2 \mathrm{D}, 3 \mathrm{D}$ US and MRI to diagnose fetal congenital malformations. They found that 2D US is more sensitive than 3D US (86.2\% and $79.3 \%$, respectively) (McNemar's test, $P=0.046$ ) and both had comparable specificities for all malformations $(92.2 \%$ and $94.4 \%$, respectively) (McNemar's test, $P=0.48$ ).

This study showed 3D US as advantageous diagnostic tool especially with head abnormalities and malformations of face and extremities. The nature of the fetal head and extremities makes their specific deformities of irregular shape, which could not be completely displayed in one cross-sectional plane. Consequently, the 2D US hardly can delineate the three dimensional shape of these deformities and their relationship to surrounding structures, with high probability of uncertainty and misdiagnosis. ${ }^{[9]}$ Conversely, the volume data obtained by $3 \mathrm{D}$ US, which comprises series of 2D images allows convenient demonstration of features of such curved lesions with their relationship to surrounding structures. ${ }^{[1,2]}$

The rendering modes of $3 \mathrm{D}$ US can be selected according to the prerequisites and nature of the scanned structures. Rendering by 3D surface mode would be suitable for fetal cranium, face and extremities, where there are prominent differences in contrast between these structures and the adjacent amnion. In addition, 3D transparent rendering mode could be selected to demarcate the evident contrast differences between bone of fetal extremities and surrounding tissues and structures. The 3D multiplanar mode would be selected to examine internal fetal structures, to compensate for the weak rendering outcome due to low contrast differences ${ }^{[1,2,9]}$.

In the present study, similar findings were obtained by both 2D and 3D US for neck, thoracic, abdominal, and twin specific malformations. Similarly, Merz et al. ${ }^{[21]}$ and
$\mathrm{XU}$ et al. ${ }^{[9]}$ found 3D US slightly more valuable in diagnosing thoracic and abdominal malformations

In the present work, 3DUS was superior to 2DUS in 9 out of 47 cases of facial malformations including exophthalmos, cleft lip/palate, low set ears and micrognathia. Although in many neonates these deformities are isolated, still, they may represent a part of complex genetic and chromosomal syndromes, or acquired embryopathies due to infections, ischemia and toxic exposure ${ }^{[22,23]}$. Consequently, prenatal detection of a facial anomaly should alert the neonatologist to carefully examine the fetus for other malformations and may help in the management of the pregnancy.

Of the 6 cases of cleft lip/palate identified after birth, 4 cases were correctly identified with both 2D and 3D US and one case was suspected to have only cleft lip by 2D, however, 3D clearly demarcated the cleft palate range and location. Furthermore, four cases of confirmed micrognathia and three cases of low set ears were diagnosed only by 3D US. Several studies concluded that 3D US provided additional diagnostic information for the detection of facial abnormalities compared to $2 \mathrm{D}$ US ${ }^{[22-25]}$.

Although surface rendering of the face has received most of concern, the three orthogonal planes of the face are not of lesser importance. They enable re-orientation of the fetal face in a standard fashion even with a fetus in unusual positions. This then permits the examiner to view a perfect fetal profile and coronal planes whatever the actual fetal position at the original volume acquisition. In many cases a perfect sagittal view of the profile using 2D imaging is not possible leading to the erroneous suggestion of micrognathia, flat profile, or other facial abnormalities ${ }^{[1,10]}$. Merz et al. ${ }^{[22]}$ studied 618 patients between 9 and 37 weeks using both a transvaginal and trans-abdominal approach using the three orthogonal planes. Midsagittal profile was accurately obtained using 2D US in only $69 \%$ of cases, while 3D reconstructed views perfectly allowed viewing the same profile for all cases. There were a total of 25 facial malformations 20 of which were clearly detected both in 2 and 3D US whereas in 5 cases there were additional features identified using only $3 \mathrm{D}$ US.

Moreover, visualizing the corpus callosum is challenging in imaging the fetal brain and this is where 3D US proves to be of benefit through the use of the multiplanar mode which allows a more accurate identification of the midsagittal plane and navigation in the other two orthogonal planes simultaneously ${ }^{[7,26]}$. In other studies, 3D US allowed better characterization of vermian abnormalities through evaluating the posterior fossa and vermian morphometry ${ }^{[27,28]}$. In Correa et al. study, 3D US was superior to $2 \mathrm{D}$ for visualization of the trans-cerebellar axial plane in 202 fetuses in mid-trimester scans ${ }^{[29]}$. 


\section{CONCLUSION}

In conclusion, three dimensional US adds value in diagnosis of some types of fetal malformations. It has to be emphasized that, rather than representing an alternative, the 3DUS is complementary to the conventional 2D sonography in the field of prenatal diagnosis. From an economic and logistic standpoint, a broad implementation (e.g. screening tests) of 3D US alone cannot be recommended.

\section{CONFLICT OF INTEREST}

There are no conflicts of interest.

\section{REFERENCES}

1. Gonçalves LF, Lee W, Espinoza J, Romero R. Threeand 4-dimensional ultrasound in obstetric practice does it help? Journal of Ultrasound in Medicine. 2005;24:1599-624.

2. Benacerraf BR. Three-dimensional fetal sonography: Use and misuse. Journal of Ultrasound in Medicine. 2002;21:1063-7.

3. Ruano R, Martinovic J, Dommergues M, Aubry MC, Dumez Y, Benachi A. Accuracy of fetal lung volume assessed by three-dimensional sonography. Ultrasound Obstet Gynecol. 2005;26:725-30.

4. Kalache KD, Eder $\mathrm{K}$, Esser $\mathrm{T}$, Proquitté $\mathrm{H}$, Stoltenburg-Didinger G, Hartung JP, et al. Threedimensional ultrasonographic reslicing of the fetal brain to assist prenatal diagnosis of central nervous system anomalies. J Ultrasound Med. 2006;25:509-14.

5. Bergann A, Bamberg C, Eder K, Proquitté H, Hartung $\mathrm{JP}$, Bollmann $\mathrm{R}$, et al. Mid-facial anthropometry in second-trimester fetuses with trisomy 21: A three-dimensional ultrasound study. Prenat Diagn. 2006;26:158-62.

6. DeVore GR, Falkensammer P, Sklansky MS, Platt LD. Spatio-temporal image correlation (STIC): New technology for evaluation of the fetal heart. Ultrasound Obstet Gynecol. 2003;22:380-7.

7. Malinger G, Lerman-Sagie T, Viñals $F$. Threedimensional sagittal reconstruction of the corpus callosum: Fact or artifact? [4]. Ultrasound in Obstetrics and Gynecology. 2006;28:742-3.

8. Ji EK, Pretorius DH, Newton R, Uyan K, Hull AD, Hollenbach $\mathrm{K}$, et al. Effects of ultrasound on maternal- fetal bonding: A comparison of two- and threedimensional imaging. Ultrasound Obstet Gynecol. $2005 ; 25: 473-7$

9. Xu HX, Zhang QP, Lu M De, Xiao XT. Comparison of two-dimensional and three-dimensional sonography in evaluating fetal malformations. J Clin Ultrasound. 2002;30:515-25.

10. Merz E, Welter C. 2D and 3D ultrasound in the evaluation of normal and abnormal fetal anatomy in the second and third trimesters in a level III center. Ultraschall der Medizin. 2005;26:9-16.

11. Scharf A, Ghazwiny MF, Steinborn A, Baier P, Sohn C. Evaluation of two-dimensional versus threedimensional ultrasound in obstetric diagnostics: A prospective study. Fetal Diagn Ther. 2001;16:333-41.

12. Salomon LJ, Alfirevic Z, Berghella V, Bilardo C, Hernandez-Andrade E, Johnsen SL, et al. Practice guidelines for performance of the routine midtrimester fetal ultrasound scan. Ultrasound Obstet Gynecol. 2011;37:116-26.

13. Merz E, Abramowicz JS. 3D/4D ultrasound in prenatal diagnosis: Is it time for routine use? Clin Obstet Gynecol. 2012;55:336-51.

14. Benacerraf BR, Benson CB, Abuhamad AZ, Copel JA, Abramowicz JS, Devore GR, et al. Threeand 4-dimensional ultrasound in obstetrics and gynecology: Proceedings of the American institute of ultrasound in medicine consensus conference. In: Journal of Ultrasound in Medicine. 2005. p. 1587-97.

15. Merz E. Current 3D/4D ultrasound technology in prenatal diagnosis. Eur Clin Obstet Gynaecol. 2005;1:184-93.

16. Dyson RL, Pretorius DH, Budorick NE, Johnson DD, Sklansky MS, Cantrell CJ, et al. Three-dimensional ultrasound in the evaluation of fetal anomalies. In: Ultrasound in Obstetrics and Gynecology. 2000. p. 321-8.

17. Gonçalves LF, Nien JK, Espinoza J, Kusanovic JP, Lee $\mathrm{W}$, Swope B, et al. What does 2-dimensional imaging add to 3- and 4-dimensional obstetric ultrasonography? J Ultrasound Med. 2006;25:691-9.

18. Johnson DD, Pretorius DH, Riccabona M, Budorick NE, Nelson TR. Three-dimensional ultrasound of the fetal spine. Obstet Gynecol Surv. 1997;89:434-8. 
19. Pretorius DH, Nelson TR. Fetal face visualization using three-dimensional ultrasonography. J Ultrasound Med. 1995;14:349-56.

20. Gonç Alves LF, Lee W, Mody S, Shetty A, SangiHaghpeykar H, Romero R, et al. Diagnostic accuracy of ultrasonography and magnetic resonance imaging for the detection of fetal anomalies: a blinded case-control study. Ultrasound Obs Gynecol. 2016;48:185-92.

21. Merz E, Bahlmann F, Weber G. Volume scanning in the evaluation of fetal malformations: a new dimension in prenatal diagnosis. Ultrasound Obstet Gynecol. 1995;5:222-7.

22. Merz E, Weber G, Bahlmann F, Miric-Tesanic D. Application of transvaginal and abdominal threedimensional ultrasound for the detection or exclusion of malformations of the fetal face. Ultrasound in Obstetrics and Gynecology. 1997;9:237-43. doi:10.1046/j.14690705.1997.09040237-.x.

23. Benacerraf BR, Mulliken JB. Fetal cleft lip and palate: Sonographic diagnosis and postnatal outcome. Plast Reconstr Surg. 1993;92:1045-51.

24. Johnson DD, Pretorius DH, Budorick NE, Jones MC, Lou K V, James GM, et al. Fetal lip and primary palate: three-dimensional versus two-dimensional US Radiology. 2000;217:236-9.

25. Lee W, McNie B, Chaiworapongsa T, Conoscenti G, Kalache KD, Vettraino IM, et al. Three-dimensional ultrasonographic presentation of micrognathia. J Ultrasound Med. 2002;21:775-81.

26. Plasencia W, Dagklis T, Borenstein M, Csapo B, Nicolaides KH. Assessment of the corpus callosum at 20-24 weeks' gestation by three-dimensional ultrasound examination. Ultrasound Obstet Gynecol. 2007;30:169-72.

27. Volpe P, Contro E, De Musso F, Ghi T, Farina A, Tempesta A, et al. Brainstem-vermis and brainstemtentorium angles allow accurate categorization of fetal upward rotation of cerebellar vermis. Ultrasound Obstet Gynecol. 2012;39:632-5.

28. Paladini D, Volpe P. Posterior fossa and vermian morphometry in the characterization of fetal cerebellar abnormalities: A prospective three-dimensional ultrasound study. Ultrasound Obstet Gynecol. 2006;27:482-9.

29. Correa FF, Lara C, Bellver J, Remohí J, Pellicer A, Serra V. Examination of the fetal brain by transabdominal three-dimensional ultrasound: Potential for routine neurosonographic studies. Ultrasound Obstet Gynecol. 2006;27:503-8. 